\title{
VOLODINA CONTRA RUSIA (I) Y S. M. CONTRA CROACIA: LA JURISPRUDENCIA INCOMPLETA DEL TEDH EN MATERIA DE CONSENTIMIENTO, RIESGO Y VIOLENCIAS CONTRA LAS MUJERES ${ }^{\prime}$
}

\author{
Volodina vs. Russia (I) and S. M. vs. Croatia: \\ The ECHR's incomplete jurisprudence on consent, \\ risk and violence against women
}

ITZIAR GÓMEZ FERNÁNDEZ Universidad Carlos III de Madrid

Mitziar.gomez@uc3m.es

Cómo citar/Citation

Gómez Fernández, I. (2021).

Volodina contra Rusia (I) y S. M. contra Croacia: la jurisprudencia incompleta del TEDH en materia de consentimiento, riesgo y violencias contra las mujeres.

lgualdadES, 5, $311-348$

doi: https://doi.org/10.18042/cepc/lgdES.5.01

(Recepción: 27/08/2021; aceptación tras revisión: 26/10/2021; publicación: 20/12/2021)

Resumen

La jurisprudencia del Tribunal Europeo de Derechos Humanos (TEDH) en materia de violencias contra las mujeres ha venido evolucionando en la última década de un modo muy interesante. Hoy ofrece un canon de enjuiciamiento bastante

Este trabajo se ha elaborado en el marco del proyecto «Teorías de la justicia y derecho global de los derechos humanos» (AEI/10.13039/501100011033). En su versión oral fue expuesto en el Seminario García Pelayo del CEPC «Dimensiones jurisprudenciales de la igualdad entre hombre y mujer. La jurisprudencia reciente del TEDH sobre violencia de género; los casos Volodina c. Rusia y S. M. c. Croacia», celebrado el 18 de marzo de 2021. 
completo en relación con las obligaciones positivas de los Estados respecto de la erradicación de este tipo de violencias. Este trabajo se detiene en dos de las modalidades de violencia de que son víctimas fundamentalmente las mujeres: la violencia en el contexto de relaciones afectivas y la explotación sexual forzosa. Ahora bien, una vez expuesto el canon diseñado por el TEDH a este respecto, la reflexión se centra en dos de los temas no adecuadamente resueltos por la jurisprudencia descrita: la definición y erradicación del riesgo a sufrir violencia, y la determinación del papel que juega el consentimiento a la hora de definir la explotación de la prostitución como fenómeno prohibido en virtud del art. 4 del CEDH.

\title{
Palabras clave
}

Jurisprudencia feminista; violencia; consentimiento; riesgo; trata de seres humanos; trabajo forzado; Tribunal Europeo de Derechos Humanos.

\begin{abstract}
The jurisprudence of the European Court of Human Rights on violence against women, has evolved over the last decade in a very interesting way. Today it offers a complete hermeneutic canon in relation to the positive obligations of States regarding the eradication of this type of violence. This paper focuses on two of the forms of violence to which women are the main victims: violence in the context of affective relationships and forced sexual exploitation. However, having set out the canon designed by the ECHR in this respect, the reflection focuses on two of the issues not adequately resolved by the jurisprudence described: the definition of the risk of suffering violence, and the determination of the role played by consent when defining the exploitation of prostitution as a prohibited phenomenon by art. 4 of the ECHR.
\end{abstract}

\section{Keywords}

Feminist jurisprudence; violence; consent; risk; human trafficking; forced labor; European Court of Human Rights. 


\section{SUMARIO}

I. CONSENTIMIENTO Y RIESGO AL HABLAR DE VIOLENCIA CONTRA LAS MUJERES. II. LAS OBLIGACIONES POSITIVAS DE LOS ESTADOS PARA LUCHAR CONTRA LA VIOLENCIA DE GÉNERO EN LA SENTENCIA DEL TEDH VOLODINA CONTRA RUSIA I: 1. La violencia contra las mujeres en las relaciones de pareja ante la jurisprudencia de Estrasburgo: análisis de contexto. 2. El supuesto de hecho en el asunto Volodina contra Rusia, de 4 de noviembre de 2019. 3. El canon de enjuiciamiento aplicable a los supuestos de violencia contra la mujer en el marco de relaciones de pareja: 3. 1. Subsunción de los hechos denunciados en el supuesto previsto en el art. 3 CEDH. 3.2. El cumplimiento por el Estado de sus obligaciones en virtud del art. $3 \mathrm{CEDH}$. 3.3. La conexión del art. $3 \mathrm{CEDH}$ y el art. $14 \mathrm{CEDH}$ : la violencia contra las mujeres como forma de discriminación. III. LA PROSTITUCIÓN FORZOSA EN LA SENTENCIA DE LA GRAN SALA S. M. CONTRA CROACIA: 1. Los antecedentes jurisprudenciales sobre trata de seres humanos en el marco del Consejo de Europa. 2. El supuesto de hecho en la sentencia del TEDH Gran Sala S. M. contra Croacia. 3. El canon desarrollado por la Gran Sala: la explotación forzosa de la prostitución ajena como situación prohibida por el art. 4 CEDH. IV. LAS LUCES Y LAS SOMBRAS DE UNA JURISPRUDENCIA EVOLUTIVA: LA DIFICULTAD DE DEFINIR CONSENTIMIENTO Y RIESGO. BIBLIOGRAFÍA.

\section{CONSENTIMIENTO Y RIESGO AL HABLAR DE VIOLENCIA CONTRA LAS MUJERES}

El desarrollo de los conceptos jurídicos relacionados con la violencia que sufren específicamente las mujeres ha sido exponencial en las dos últimas décadas²,

2 Del mismo modo que lo ha sido el desarrollo de los estudios sobre violencia de género desde otros enfoques como los bioconductuales, los sociológicos, los psicológicos, etc. (Russo y Pirlott, 2006). Sin duda alguna, un análisis multidisciplinar del fenómeno multifacético de la violencia de género sería más completo, y por ello posiblemente más certero. Pero no es la pretensión del presente trabajo, que se limita a abordar la perspectiva de la construcción de los conceptos jurídicos - y de dos muy concretospor parte de la jurisprudencia del Tribunal Europeo de Derechos Humanos. Con ese enfoque tan reduccionista, no pretendo negar la importancia de los enfoques abiertos 
y la jurisprudencia de las altas cortes ${ }^{3}$, así como los pronunciamientos del Comité de la CEDAW ${ }^{4}$, han sido determinante en tal desarrollo. No obstante, este no siempre ha sido lineal, claro o uniforme ni desde el punto de vista de las políticas públicas ni desde el enfoque meramente legislativo ni mucho menos desde la perspectiva estrictamente jurisprudencial, de modo tal que siguen existiendo, de cara a los operadores jurídicos, una infinidad de dudas en relación con muchas nociones que aún son fundamentales para avanzar en la erradicación de este fenómeno desde la triple perspectiva apuntada. La falta de uniformidad conceptual $^{5}$ no ha impedido, en ningún caso, efectuar avances en materia de prevención, represión y asistencia a las víctimas, aunque en el momento actual la sensación de frustración de las autoridades públicas y del movimiento feminista en relación con estos avances es notable: no parece posible alcanzar ni a corto ni a medio plazo una situación de erradicación de la violencia contra

y multidisciplinares, que me parece esencial, sino que intento precisamente poner el acento en la necesidad de completar la noción jurisprudencial de consentimiento y riesgo que realiza el TEDH, al resultar la misma, como se explicará en estas páginas, ciertamente incompleta.

3 Véase en relación con esta tarea la obra colectiva editada por Carmona Cuenca (2015), titulada La perspectiva de género en los sistemas europeo e interamericano de derechos humanos, publicada por el CEPC

4 En relación con esta cuestión, véase Cardoso Onofre de Alencar (2019).

5 La propia nomenclatura de la violencia de género está abierta a debate, y ello es ejemplo paradigmático de las dificultades conceptuales que entrańa el estudio de la violencia contra las mujeres. La legislación española, por ejemplo, ha limitado el objeto de la Ley Orgánica 1/2004, de 28 de diciembre, de Medidas de Protección Integral contra la Violencia de Género, a tratar la violencia que sufren las mujeres e infligen sus parejas o exparejas de sexo masculino (véase, en este sentido, el art. 1 de la ley). Por su parte, el «Convenio del Consejo de Europa sobre prevención y lucha contra la violencia contra la mujer y la violencia doméstica», de 11 de mayo de 2011 (en adelante Convenio de Estambul), formula una definición más amplia, entendiendo por "violencia contra la mujer» cualquier acto de violencia basado en el género que implique o pueda implicar para las mujeres dańos o sufrimientos de naturaleza física, sexual, psicológica o económica, incluidas las amenazas de realizar dichos actos, la coacción o la privación arbitraria de libertad, en la vida pública o privada [art. 3a) del Convenio de Estambul]. El TEDH, interpretando el CEDH, se refiere a la violencia ejercida contra las mujeres en el ámbito de las relaciones de pareja o expareja bajo el concepto genérico de violencia doméstica (Queralt, 2012: 217) cuando en el contexto español se evita con intencionalidad política el recurso a esta noción, como resultado de una estrategia de visibilización y externalización de la cuestión que se desarrolló en torno a la aprobación de la Ley Orgánica 1/2004. 
las mujeres, ni siquiera en contextos jurídicos con legislaciones adecuadas y políticas públicas activas en este sentido. Estas dificultades se manifiestan, entre otros, en dos ámbitos: la violencia infligida por los varones sobre sus parejas o exparejas, y la violencia ejercida sobre las mujeres con fines de explotación sexual de la que extraer un beneficio económico ${ }^{6}$. Y en relación con estos dos ámbitos existen dos conceptos clave que pueden ser examinados, entre otras, desde la perspectiva jurídica: consentimiento y riesgo.

Consentir supone permitir, aceptar o condescender para que se haga algo y tiene cierta connotación pasiva (Sánchez Perea, 2019; Wertheimer, 2003). En el contexto de las situaciones de violencia supone la aceptación del comportamiento violento o quizá solo de la situación de poder que permite el ejercicio de esa violencia, y asumir que cabe consentimiento en contextos violentos supone profundizar en la necesaria construcción de sus límites o en la prevalencia de la libertad individual, incluso sobredimensionándola sobre otros valores como la igualdad o la equidad. Cabría, incluso, interrogarse sobre si la mera existencia del consentimiento basta para suprimir el carácter intrínsecamente violento de la conducta consentida. La propia definición de lo que es violencia sexual se basa en el alcance de la noción de consentimiento. El art. 36.1 del Convenio de Estambul sostiene que la violencia sexual aparece cuando se realiza cualquier acto de carácter sexual no consentido sobre una persona o cuando se fuerza a esa persona,

6 También en el ámbito de la violencia sexual de que son objeto las mujeres se pone de manifiesto lo complejo de su erradicación y las dificultades que normativa y políticas públicas encuentran para superarla. Y también respecto de este tipo de violencia resulta relevante la noción de consentimiento, que ha sido abordada en este marco por el TEDH y es clave, asimismo, en el Proyecto de Ley Orgánica de garantía integral de la libertad sexual (BOCG. Congreso de los Diputados, núm. A-62-2 de 30/08/2021), sometido a debate de totalidad en el Pleno del Congreso el 14 de octubre de 2021 y pendiente de tramitación parlamentaria y eventual aprobación definitiva. Sin descartar la importancia de la noción de consentimiento en relación con la violencia sexual, no abordaré el tema en este trabajo por una cuestión metodológica. El artículo no pretende analizar en toda su amplitud las nociones de consentimiento y riesgo, sino analizar dos pronunciamientos muy concretos del TEDH y extraer de ese análisis una crítica a la falta de definición jurídica completa, en el ámbito del Consejo de Europa, de dos nociones clave en el avance del trabajo dogmático, doctrinal, jurisprudencial y político sobre violencia machista. En todo caso, y en relación con la cuestión del consentimiento en el ámbito de las relaciones sexuales, como presupuesto filosófico para avanzar en la reflexión, muy concreta y apegada al caso concreto que aquí se propone, se recomienda la lectura de Wertheimer (2003). 
que no ha consentido, a realizar cualquier acto sexual con un tercero. Pero la cuestión problemática aparece después, cuando el propio Convenio afirma que «el consentimiento debe prestarse voluntariamente como manifestación del libre arbitrio de la persona considerado en el contexto de las condiciones circundantes» (art. 36.2 Convenio de Estambul). Cumple entonces analizar cuáles son las condiciones que pueden perturbar el libre arbitrio de una mujer, y ello no resulta en absoluto sencillo. La presencia de condicionantes culturales o económicos, la amenaza, la percepción del riesgo en que se encuentra la propia vida, la integridad física propia o la de terceras personas, la falta de referentes, la vulnerabilidad por condiciones propias de la persona o la derivada de circunstancias puntuales y externas, la edad, las capacidades diversas, el sexo... son condiciones circundantes cuya apreciación suele quedar en manos de los órganos judiciales.

Por lo que hace al riesgo, la dificultad no es menor. La valoración de la contingencia o proximidad de un daño también se formula sujeta a las condiciones circundantes, y no se hace de manera idéntica cuando se poseen datos o información distinta en relación con esas condiciones o cuando la percepción sobre esas condiciones es diferente.

La elección de estas dos nociones como eje de reflexión no es caprichosa. Pero tampoco es presupuesto de la reflexión, sino, de algún modo, el resultado de una lectura atenta de dos sentencias muy recientes del TEDH que se me propuso comentar ${ }^{7}$. Con la intención de esquivar una metodología de análisis meramente descriptiva, opté por buscar en las dos sentencias objeto de análisis, Volodina c. Rusia I ${ }^{8}$ (STEDH de 4 de noviembre de 2019) y S. M. c. Croacia (fechada el 25 de junio de 2020), los elementos jurisprudenciales más débiles que, por eso mismo, se me antojan particularmente problemáticos a la hora de ser trasladados a la jurisprudencia nacional de los Estados parte del Consejo de Europa. Consentimiento y riesgo son los conceptos frágiles de una y otra sentencia y surgen tras el análisis de las mismas, no como presupuesto de su examen.

\footnotetext{
Véase nota 1.

8 Nótese que tras la sentencia que aquí se comenta es la STEDH de 4 de noviembre de 2019, relativa a la demanda núm. 41261/17, pero que existe una sentencia más reciente entre las mismas partes. La STEDH Volodina c. Rusia (II), de 14 de septiembre de 2021, resuelve la demanda num. 40419/19 centrándose en la violación del art. 8 (respeto a la vida privada) derivada de la ausencia de protección a la víctima por parte de las autoridades rusas en relación con el acoso sufrido a través de redes sociales que fue denunciado por la señora Volodina, pero no adecuadamente perseguido. Esta sentencia puede ser consultada en: https://bit.ly/3pZkDzW (último acceso el 15/10/2021).
} 
Puede ser este un método de análisis un tanto atípico, efectivamente. Pero me parece a su vez un método interesante para comprender mejor las dificultades que puede tener la jurisprudencia del TEDH para calar en los sistemas nacionales. Esta elección del objeto principal (exégesis de las dos sentencias citadas) y del método de estudio (extracción de las nociones problemáticas) debe estar presente en la lectura del texto, en la que se echará de menos el análisis de otras dimensiones no menos interesantes de las nociones de riesgo y consentimiento? . Pero no es mi intención agotar la reflexión sobre ambos temas, ni siquiera formular una aproximación dogmática a las mismas. Este es un primer paso de sucesivas reflexiones. Y empieza casi por el final: el examen de la aplicación de los conceptos en la jurisprudencia de una alta corte.

En el ámbito que nos ocupa, como en otros muchos, acudir al estudio del sistema jurisdiccional del Consejo de Europa como referente es fundamental por el alcance evolutivo de sus pronunciamientos en este ámbito ${ }^{10}$ y por la conexión establecida entre los derechos de corte clásico, contenidos en el Convenio Europeo para la Protección de los Derechos Humanos y de las Libertades Fundamentales (CEDH), y los derechos de las mujeres a vivir una vida libre de violencias ${ }^{11}$. Establecida por el TEDH esta conexión entre la violencia de género y las violaciones graves de los derechos humanos, los tribunales nacionales (en especial los españoles sujetos al mandato del art. 10.2 CE) están llamados a asumir que estas mismas formas de violencia pueden suponer y suponen, de hecho, vulneraciones claras de los derechos fundamentales de las mujeres.

9 Véase nota al pie número 6.

10 La noción de interpretación evolutiva del CEDH, que asume el propio Tribunal de Estrasburgo, se encuentra claramente expuesta en el $₫ 288$ de la STEDH S. M. c. Croacia, objeto del presente trabajo.

11 Podría incluso llegar a afirmarse que el Convenio de Estambul encuentra una garantía jurisdiccional indirecta a través de la conexión de sus preceptos con los del CEDH, y la posterior sumisión de supuestos de hecho de violencia contra las mujeres a juicio del Tribunal de Estrasburgo. Los preceptos del CEDH que funcionan habitualmente como vínculo de conexión con el Convenio de Estambul son el art. 2 (derecho a la vida), el art. 3 (prohibición de la tortura y de otros tratos inhumanos o degradantes), el art. 4 (prohibición de la esclavitud, la servidumbre y el trabajo forzado), el art. 8 (respeto a la vida privada y familiar), y cualquiera de ellos en relación con el art. $14 \mathrm{CEDH}$ (interdicción de discriminación por razón de sexo). 


\section{LAS OBLIGACIONES POSITIVAS DE LOS ESTADOS PARA LUCHAR CONTRA LA VIOLENCIA DE GÉNERO EN LA SENTENCIA DEL TEDH VOLODINA CONTRA RUSIA I}

\section{LA VIOLENCIA CONTRA LAS MUJERES EN LAS RELACIONES DE PAREJA ANTE LA JURISPRUDENCIA DE ESTRASBURGO: ANÁLISIS DE CONTEXTO}

La STEDH Volodina c. Rusia I no es la primera en la que el TEDH se pronuncia sobre la violencia doméstica ejercida contra las mujeres. Pero junto los asuntos Barsova c. Rusia, 22 de octubre de 2019, Polshina c. Rusia, de 16 de junio de 2020, y Volodina c. Rusia II, de 14 de septiembre de 2021, forman un conjunto en el que, por primera vez, el Estado ruso es condenado por faltar a sus obligaciones positivas respecto de la erradicación de la violencia machista en el seno de las relaciones de pareja. Las sentencias ponen de manifiesto que no se trata de casos aislados, sino de supuestos repetitivos que revelan la insuficiencia de las políticas públicas rusas en este ámbito ${ }^{12}$, pudiendo reprocharse al Estado, incluso, la ausencia de firma del Convenio de Estambul. En los tres primeros casos la condena se basa en la vulneración del art. $3 \mathrm{CEDH}$, que establece que «nadie podrá ser sometido a tortura ni a penas o tratos inhumanos o degradantes», así como en la vulneración del art. $14 \mathrm{CEDH}$ en la medida en que se reconoce que la falta de disfrute del art. $3 \mathrm{CEDH}$ supuso una discriminación por razón de sexo ${ }^{13}$.

Estos pronunciamientos siguen la línea jurisprudencial ${ }^{14}$ iniciada en la STEDH Kontrová c. Eslovaquia, de 31 de mayo 2007, que abordó por primera vez la violencia intrafamiliar entre esposos ejercida por el hombre contra la mujer o sus hijos, desde el ángulo del art. $2 \mathrm{CEDH}$ (derecho a la vida). En aquel supuesto se había causado la muerte de los hijos menores de la recurrente, y el análisis de la atención de las autoridades eslovacas a la víctima superviviente

12 La propia sentencia en el asunto Volodina recoge una serie de datos estadísticos y cualitativos presentados por la recurrente en relación con la violencia contra las mujeres en Rusia ( $\$ 40-45)$, así como otros materiales bien aportados por terceros intervinientes, bien producto de la propia investigación del Tribunal (\$ 61-66).

13 Interesa recordar que el art. $14 \mathrm{CEDH}$ es esencialmente relacional y por ello en la jurisprudencia del TEDH siempre se vincula al contenido de otros derechos de los proclamados en el CEDH. Profundiza en el alcance del art. $14 \mathrm{CEDH}$ y en su contenido Carmona (2018).

14 Para analizar esta línea jurisprudencial en distintos momentos de su evolución, se recomienda la lectura de los textos de Carmona Cuenca $(2015,2018)$; Enrich i Mas (2018); López-Jacoiste Díaz (2009); Medina (2014), y Queralt Giménez (2012). 
puso de manifiesto la falta de un recurso efectivo que habilitara una compensación del daño moral sufrido. A este asunto siguió la STEDH Branko Tomasic $y$ otros c. Croacia, de 15 de enero de 2009, en un supuesto de hecho similar que fue analizado desde el mismo ángulo y siempre sin conexión con el art. $14 \mathrm{CEDH}$. El enfoque empieza a abrirse someramente, incluso antes de la entrada en vigor del Convenio de Estambul, en la STEDH Bevacqua y S. $c$. Bulgaria, de 12 de junio de 2008. Tal y como lo define Carmona (2018), este pronunciamiento, que resuelve una queja respecto de un supuesto de malos tratos sin resultado de muerte, abrió una nueva línea argumental aplicable a las mujeres que sufren violencia por parte de sus parejas o exparejas, identificándolas como personas en situación de vulnerabilidad y reforzando por ello las obligaciones positivas del Estado respecto de las mismas.

Pero la verdadera inflexión de la línea jurisprudencial se produce un año más tarde con la STEDH Opuz c. Turquía, de 9 de junio de 2009 (Queralt, 2012: 217, 233; Alcoceba Gallego, 2013). En este caso, Estrasburgo estructura su argumentario en torno a los arts. 2 y $3 \mathrm{CEDH}$, apreciando por primera vez la conexión con el art. $14 \mathrm{CEDH}$. La estructura argumental de esta sentencia se encuentra también en las tres que condenan a Moldavia (SSTEDH Eremia c. Moldavia, de 18 de mayo de 2013; Mudric c. Moldavia de 16 de julio de 2013; T. M. y C. M. c. Moldavia de 28 de enero de 2014), aunque no está presente, en cambio, en la STEDH E. S. y otros c. Eslovaquia, de 15 de septiembre de 2009, que se limitó a formular un estudio de caso sin conexión con el tema de la violencia estructural como elemento discriminatorio hacia las mujeres (Queralt, 2012: 227).

Por su parte, las SSTEDH A. c. Croacia, de 14 de octubre de 2010 y Hajduová c. Eslovaquia, de 30 de noviembre de 2010, reconocieron la lesión del art. $8 \mathrm{CEDH}$ (en su vertiente de preservación de la integridad física y psíquica de las personas). A pesar de la diferencia de encuadre, la preocupación por la vulnerabilidad de las víctimas está presente y se traduce en un estándar mayor de exigencia en lo que hace a las obligaciones positivas del Estado en el asunto Hajduová (ibid.: 229), mientras que en el asunto $A$. c. Croacia no se reconoce la vulneración del art. $14 \mathrm{CEDH}$ por insuficiencia probatoria (ibid.: 241).

En todos estos pronunciamientos el Tribunal pone de manifiesto que las distintas formas que adopta la violencia contra las mujeres en el seno de las relaciones de pareja son un problema generalizado que afecta a dodos los Estados miembros del Consejo de Europa, que resulta difícil de visibilizar y que pone de manifiesto la especial vulnerabilidad de las víctimas, lo que exige del Estado que participe en su protección activamente. 


\section{EL SUPUESTO DE HECHO EN EL ASUNTO VOLODINA CONTRA RUSIA, DE 4 DE NOVIEMBRE DE 2019}

En noviembre del año 2014, cuando Valerya Igorevna Volodina tenía treinta años, inicia una relación sentimental con el señor M. S., conviviendo sin contraer matrimonio hasta mayo de 2015. En ese momento ella abandona el domicilio conyugal, y regresa después ante las amenazas de muerte hacia ella y su hijo, proferidas por su pareja, M. S.

En enero de 2016 Valerya, presenta una denuncia en comisaría, exponiendo que M. S. había roto el parabrisas de su coche y se había llevado sus documentos. De la reparación del daño y la retirada de la denuncia se deriva que no se siguieran acciones penales $(\$ 11)$. Esta decisión será confirmada en junio de 2016 por el ministerio fiscal. Ese mismo mes, y estando embarazada de nueve semanas, la Sra. Volodina abandona su ciudad y viaja a Moscú, donde M. S. la encuentra, la secuestra quitándole el móvil y sus efectos personales y haciéndola regresar a su residencia. Tras una agresión física se diagnostica a la víctima riesgo de aborto involuntario, por lo que se practica una I. V. E. por razones terapéuticas. Tras la denuncia policial inicial se retiran los cargos, negándose la víctima a someterse a reconocimiento forense. En este caso tampoco se seguirán acciones penales. No se hará tampoco tras la denuncia escrita presentada el 18 de mayo de 2016, tras un intento de estrangulamiento.

Después de esta última agresión, Valerya vuelve a Moscú para ocultarse, pero M. S. la encuentra y se produce una nueva agresión el 30 de julio de 2016, denunciada, a la que sigue la manipulación del vehículo de la víctima que también es denunciada. En ninguno de los dos casos la policía concluye la necesidad de abrir un proceso penal. En septiembre de 2016 la demandante encontró un dispositivo de seguimiento electrónico en su bolso de mano. Ante la sospecha de que lo había instalado M. S., la Sra. Volodina informa a la policía, que realiza un informe sin iniciar ninguna investigación.

El 1 de junio de 2017 se planteó la demanda ante el TEDH.

A principios de 2018, el Sr. M. S. publica fotografías privadas de la Sra. Volodina en una red social sin su consentimiento. En este caso se inicia una investigación penal al amparo del art. $137 \mathrm{CP}$ ruso, y en el marco de dicho procedimiento la demandante solicitó la protección del Estado en su condición de víctima de un delito. Aunque se le reconoció su condición de víctima, no se adoptó ninguna medida de protección efectiva ${ }^{15}$. En marzo de 2018, ante nuevas amenazas de muerte, una agresión y un robo, la Sra. Volodina presenta

15 A esta cuestión se refiere la STED Volodina c. Rusia II. 
nuevas denuncias, ninguna de las cuales concluirá en ningún procedimiento penal.

Por último, la Sra. Volodina cambia legalmente su nombre el 30 de agosto de 2018, al temer por su seguridad y con la intención de ocultarse de su agresor. El nombre actual no aparece en el pronunciamiento a petición de la recurrente.

\section{EL CANON DE ENJUICIAMIENTO APLICABLE A LOS SUPUESTOS DE VIOLENCIA CONTRA LA MUJER EN EL MARCO DE RELACIONES DE PAREJA ${ }^{16}$}

En la demanda ante el TEDH, se denuncia la violación de los arts. 3 $\mathrm{CEDH}$ y $13 \mathrm{CEDH}$ (existencia de un recurso efectivo ante una instancia nacional para defender los derechos reconocidos en la Convención), debido a las deficiencias del marco jurídico nacional y la ausencia de disposiciones específicas que regulen la violencia doméstica (como las órdenes de alejamiento), así como la vulneración del art. $14 \mathrm{CEDH}$.

Tras una enumeración exhaustiva de la normativa internacional sobre violencia contra la mujer ${ }^{17}$, y la descripción de la legislación interna ${ }^{18}$, la sentencia formula el siguiente canon de enjuiciamiento:

16 La sentencia viene acompańada de dos votos particulares y uno concurrente, a pesar de que en el fallo de esta solo constan las discrepancias relativas a las medias de reparación individuales (que se adoptan por cinco votos a dos) y a la satisfacción equitativa, mientras que se considera por unanimidad las lesiones del art. $3 \mathrm{CEDH}$ y del art. 14 $\mathrm{CEDH}$.

17 La sentencia cita la Convención sobre la Eliminación de Todas las Formas de Discriminación contra la Mujer [ratificada por Rusia el 23 de enero de 1981 (\$ 51)], conocida como CEDAW, las recomendaciones generales núm. 19 (\$ $\$ 2), 28(\$ 53)$, $33(\$ 54), 35$ (\$ 55) del Comité CEDAW sobre la violencia contra la mujer, la comunicación en el asunto $V . K c$. Bulgaria $(\$ 56)$, así como varios informes de los relatores especiales de la ONU (\$ 57-58). También se invocan varios documentos del COE, en particular la Recomendación (2002) 5, adoptada por el Comité de Ministros el 30 de abril de 2002 sobre la protección de las mujeres contra la violencia ( $\$$ 59), y el Convenio del Consejo de Europa sobre Prevención y Lucha contra la Violencia contra las Mujeres y la Violencia Doméstica $(\$ 60)$, tratado este en el que apenas se detiene el Tribunal, dada la ausencia de ratificación por Rusia, más que para recordar que la definición de violencia contra las mujeres que recoge el art. 3 del Convenio es idéntica a la que se encuentra en la Recomendación (2002) 5.

18 Se hace particular hincapié en el capítulo 16 del CP ruso, que recoge los delitos contra las personas $(\$ 46-50)$, poniéndose de manifiesto que, si bien en julio de 2016 se 


\subsection{Subsunción de los hechos denunciados en el supuesto previsto en el art. 3 CEDH}

Como vimos un poco más arriba, ante la ausencia de previsión expresa, el Tribunal de Estrasburgo debe construir el derecho de las mujeres a no sufrir violencia conyugal a partir de los específicamente reconocidos en el CEDH, tomando como referencia el derecho invocado por la demandante, en este caso el art. 3 CEDH.

De las tres dimensiones reconocidas en este derecho por la jurisprudencia previa, el TEDH identifica el derecho a no sufrir tratos degradantes con el derecho a no sufrir malos tratos o no sufrir violencia intrafamiliar ${ }^{19}$. Se admite, además, que los tratos degradantes pueden darse, aunque no existan lesiones corporales o sufrimiento físico o psicológico grave, cuando se infligen tratamientos que "humillen o degraden a una persona, que muestren falta de respeto o disminuyan su dignidad humana, o que susciten sentimientos de temor, angustia o inferioridad capaces de quebrantar la resistencia moral y física de una persona» (\$73). El Tribunal recuerda, en este punto, que en pronunciamientos anteriores ya se consideró que "puede ser suficiente con que la víctima se sienta humillada según su parecer, aunque no lo sea a la vista de los demás» (\$ 73). A partir de este marco de enjuiciamiento, el Tribunal constata que los hechos descritos y tenidos por hechos probados, denotan el nivel mínimo de gravedad suficiente como para entrar en el ámbito de aplicación del art. $3 \mathrm{CEDH}$.

\subsection{El cumplimiento por el Estado de sus obligaciones en virtud del art. 3 CEDH}

En la medida en que los tratos degradantes no han sido infligidos a la víctima por parte de agentes del Estado, sino que el victimario es un individuo

enmendó parte del capítulo reconociéndose la agravante de parentesco, previéndose que la investigación y enjuiciamiento de estos delitos no admitía el arrepentimiento de la víctima tras la denuncia, e incluyéndose un nuevo delito de agresión reiterada para juzgar la acumulación de pequeñas lesiones menores infligidas por la misma persona, en febrero de 2017 se descriminalizaron los actos de agresión entre cónyuges o parejas. También se pone de relieve la ausencia de medidas cautelares de protección de las víctimas, como la existencia de una orden de alejamiento o de protección.

19 Algunos autores se refieren también a la violencia de género en el ámbito de la violencia doméstica como una forma de tortura, refiriéndose a la necesidad de reconceptualizar la violencia conyugal en estos términos (Copelon, 1994). También insiste en esta idea el voto particular del juez Pinto de Alburquerque. 
particular, no puede identificarse la responsabilidad del Estado en estos hechos más que si se pasa por la doctrina de las obligaciones positivas ${ }^{20}$, tal y como ha venido manteniendo la jurisprudencia del Tribunal en materia de violencia de género desde la STEDH Kontrová c. Eslovaquia. En el supuesto que nos ocupa, que en nada altera la línea previa, se establece que el Estado tiene «a) la obligación de establecer y aplicar en la práctica un marco jurídico adecuado que ofrezca protección contra los malos tratos por parte de los particulares; b) la obligación de adoptar las medidas razonables que cabría esperar a fin de evitar un riesgo real e inmediato de malos tratos que las autoridades conocían o debían conocer, y c) la obligación de llevar a cabo una investigación efectiva cuando se ha presentado una denuncia cuestionable de malos tratos» (\$77).

Respecto de la exigencia de desarrollar un marco normativo adecuado, el Tribunal establece además un estándar material básico para dicho marco, afirmando que existe un «acuerdo internacional común» (\$78) a este respecto, es decir un ius cogens que determina:

- La inscripción de las medidas normativas en el ámbito del derecho penal, debiendo establecerse sanciones «efectivas, proporcionadas y disuasorias» $(\$ 78)$ frente a los actos de violencia doméstica, que sean lo suficientemente específica como para garantizar la protección de las víctimas (\$78).

- No cabe la mera persecución privada de las faltas o delitos de violencia conyugal (\$82 y 99).

- Debe preverse la continuidad del procedimiento incluso cuando se retire la denuncia $(\$ 84)$.

- Deben contemplarse medidas cautelares de protección y/u órdenes de protección sucesivas una vez exista sentencia condenatoria $(\$ 88)$.

- En el procedimiento debe aplicarse la inversión de la carga de la prueba a favor de la víctima, dada la situación de intimidad en que suelen producirse este tipo de lesiones y las dificultades para proporcionar el adecuado acervo probatorio ( $\$ 82$ y 111).

La exigencia del respeto de un cierto margen de apreciación a los Estados lleva al Tribunal a reconocer, pese a todo, que las soluciones legislativas pueden ser diversas siempre que la protección de las víctimas sea eficaz $(\$ 79)^{21}$.

20 Para profundizar en esta noción véanse los trabajos de Sudre (1995) y Mowbay (2004).

21 A este respecto nótese que el juez Pinto de Alburquerque sostiene en su voto que debieran haberse dado pautas más precisas para desarrollar una futura normativa sobre violencia de género. Y frente a ello, los informes sobre cumplimiento de esta sentencia 
Considerado el estándar mínimo expuesto, la sentencia concluye que en Rusia no se respeta la obligación de desarrollo del marco jurídico adecuado, porque: a) no existe legislación específica para abordar la violencia que se produce en el contexto familiar, ni se considera la violencia doméstica como delito independiente, ni existe en la actualidad una agravante específica que contemple estos comportamientos ( $\$ 80)$; y b) la legislación vigente no puede considerarse como adecuada a la persecución de este tipo de comportamientos por distintas razones, en particular por no preverse medidas de protección o alejamiento tras una eventual condena, y por exigir la iniciativa privada de la víctima a la hora de iniciarse cualquier tipo de procedimiento (\$ 81-84), recordando el Tribunal en este punto que, si bien la persecución de oficio no es siempre exigible para observar el respeto al art. $3 \mathrm{CEDH}$, en el contexto de la violencia doméstica la acusación privada impone una carga excesiva a la víctima, supone mayor lentitud del procedimiento y no evita el riesgo de la repetición de incidentes similares.

La sentencia continúa aplicando el canon general, aunque el juicio anterior hubiera sido suficiente para declarar la vulneración del art. $3 \mathrm{CEDH}$, y prosigue el enjuiciamiento afirmando que en el ordenamiento ruso no existe ningún mecanismo para prevenir el riesgo de agresiones a través de la aplicación de órdenes de alejamiento o protección cautelar. Por tanto, no se cumple con la obligación de prevenir el riesgo reconocido de malos tratos (\$ 86-91).

Es aquí donde aparece, como vemos, la noción de riesgo para afirmar que el «riesgo de una amenaza real e inmediata ${ }^{22}$ debe evaluarse teniendo en

ponen de manifiesto las dificultades para ajustar la normativa rusa a estos mínimos requisitos. Prueba de ello es que el proyecto de ley presentado para regular la violencia doméstica no ha sido aprobado hasta la fecha, ante la insistencia de la mayoría del Parlamento, en que la Constitución rusa ya reconoce de manera bastante el principio de igualdad, y que la única pretensión de este tipo de normativa es destruir a la familia. Véase a este respecto el comentario contenido en: https://bit.ly/3mzgLUj, sobre la situación de la tramitación de la ley.

22 A este respecto resulta interesante acudir a la crítica contenida en el voto particular de Pinto de Alburquerque y Dedov, cuando sostiene que el canon establecido en la STEDH Osman c. Reino Unido, de 28 de octubre de 1998, al que denomina "prueba Osman» no sirve para ser aplicado en los supuestos de violencia de género. Tal y como se explica en el voto, la prueba Osman examina si las autoridades «conocían, o deberían haber conocido en su momento, la existencia de un riesgo real e inmediato para la vida de una o varias personas identificadas por los actos delictivos de un tercero y por consiguiente si no adoptaron las medidas en el ámbito de sus competencias que, a su juicio, podían esperarse de ellas». Dicho en otros términos, y tal y como lo 
cuenta el contexto particular de la violencia doméstica. En tal situación, no se trata solo de la obligación de ofrecer una protección general a la sociedad, sino que, sobre todo, deben de tenerse en cuenta la reiteración de los episodios de violencia dentro de la familia» (\$86). Pero el Tribunal no va más allá en la concreción. No especifica la fórmula de evaluación del riesgo ni los elementos que han de ser tenidos en cuenta para esa evaluación ni distingue adecuadamente entre la noción de riesgo y la identificación de la concurrencia de causas que justifiquen la adopción de medidas de protección de la presunta víctima.

Cuando la sentencia, en esta fase de aplicación del canon, debería centrarse en la definición de cómo el Estado puede evitar el riesgo de que la víctima sufra de nuevo la violencia por parte de su agresor, lo cierto es que se limita insistir en la ausencia de medidas de protección, cuestión esta presente también en el juicio sobre la calidad de la normativa rusa en materia de violencia doméstica $(\$ 86-88)$.

En el supuesto de hecho, el Tribunal constata que las autoridades rusas no han puesto medios suficientes para impedir la repetición constatada de los ataques violentos a la demandante, y considera inadecuada la aplicación del sistema de protección de testigos previsto en la legislación rusa a la protección de las víctimas de violencia doméstica. Ni siquiera es necesario para el razonamiento del Tribunal evaluar si se ha formulado una adecuada evaluación del riesgo de la víctima porque la mera reiteración de denuncias exenta de la

interpreto, la prueba Osman delimita las obligaciones positivas del Estado en virtud del riesgo detectado en un supuesto concreto, siendo mayores las obligaciones de las autoridades públicas cuanto mayor es el riesgo identificado. Ahora bien, lo que el juez Pinto de Alburquerque pone en duda es que la prueba Osman no logra su propósito en materia de violencia doméstica si se toma al pie de la letra la noción de «riesgo real e inmediato». Si se hace así "cualquier acción de protección ofrecida por el Estado sería demasiado tardía y, en segundo lugar, el Estado tendría una excusa legítima para no actuar a tiempo, ya que es inverosímil suponer que la víctima pueda estar constantemente acompañada por un agente del Estado que pueda acudir en su ayuda. Por lo tanto, la "inmediatez" de la prueba Osman no sirve en el contexto de la violencia doméstica». A cambio, el juez portugués propone sustituir la noción de riesgo real e inmediato por la de riesgo presente, de modo que el Estado será responsable siempre que conozca o debiera conocer que «un segmento de su población, como son las mujeres, es objeto de violencia reiterada y no logra impedir que los miembros de ese grupo de personas sufran dańos cuando se enfrentan a un riesgo presente (pero aún no inminente). En consecuencia, el criterio de diligencia debida con respecto al cual se evalúa la acción o inacción del Estado abarca un período de tiempo más amplio, el cual comienza en el momento en que existe un riesgo de violencia doméstica, pero no es aún inminente». 
adopción de cualquier tipo de medida, e incluso de la falta de seguimiento de las investigaciones policiales tendentes a aclarar los hechos e iniciar un procedimiento penal, ya pone de manifiesto la ausencia de mecanismos de prevención $(\$ 91)$.

Por último, el Tribunal considera que ni las autoridades policiales ni las autoridades judiciales desarrollaron una investigación adecuada de las denuncias, limitándose a escuchar las declaraciones de la recurrente y su expareja, aconsejando a este que reparase el daño causado y se reconciliara con la denunciante (\$ 92-101).

Partiendo de que la obligación de llevar a cabo una investigación adecuada es un elemento esencial de las responsabilidades del Estado en virtud del art. $3 \mathrm{CEDH}(\$ 92)$, y que tal investigación está llamada a ser rápida y exhaustiva para ser realmente eficaz, además de especialmente diligente en los casos de violencia doméstica, el Tribunal concluye que en el supuesto de hecho no se dieron estas circunstancias. A las denuncias no siguieron más que una serie de averiguaciones previas a la investigación que, en cada caso, concluyeron con la negativa a entablar un procedimiento penal al no considerarse los hechos denunciados como suficientemente graves. $Y$ esta investigación previa no cumplió con los requisitos de la investigación eficaz ex art. $3 \mathrm{CEDH}$. El que no se realizasen reconocimientos médicos inmediatamente después de las agresiones, no se adoptase una visión de conjunto de la sucesión de actos violentos y la actuación policial se limitase a tomar declaración a las partes implicadas, pone de manifiesto la ausencia de eficacia de la investigación. La sentencia constata que el interés de la policía era cerrar los trámites lo antes posible, trivializando las denuncias, calificando siempre los hechos de acuerdo con el tipo menos grave, convenciendo al agresor para reconciliarse con su pareja y reparar el daño causado, o elevando la exigencia de las pruebas requeridas para iniciar un proceso penal (por ejemplo, exigiendo que las amenazas de muerte fueran reales y específicas para poder ser enjuiciadas). Y por todo ello concluye que el Estado no cumplió con su deber de investigar los malos tratos sufridos por la demandante.

En relación con el art. $13 \mathrm{CEDH}$, invocado por conexión con el art. $3 \mathrm{CEDH}$, el Tribunal consideró, por unanimidad, que no era necesario examinar la queja interpuesta por este motivo.

\subsection{La conexión del art. 3 CEDH y el art. 14 CEDH: la violencia contra las mujeres como forma de discriminación}

Como ha podido notarse hasta el $\$ 102$, la sentencia se refiere a la violencia doméstica en el marco proporcionado por el art. $3 \mathrm{CEDH}$, pero no hace una mención específica de las particularidades de la violencia contra las 
mujeres (dentro o fuera del ámbito doméstico) hasta que llega al análisis de la lesión del art. $14 \mathrm{CEDH}$ en relación con el art. $3 \mathrm{CEDH}$. En suma, es en este apartado en el que se realiza una interpretación de la convención «sensible al género", en la expresión que utiliza en su voto particular el juez Pinto de Alburquerque.

En este punto, la sentencia reconoce expresamente ${ }^{23}$ que la violencia contra la mujer, dentro de cuya categoría más amplia incluye la específica de la violencia doméstica, es una forma de discriminación ( $\$ 110)$, de modo que la «falta de protección por parte del Estado a la mujer contra la violencia doméstica infringe su derecho a la protección de la ley en condiciones de igualdad, independientemente de si dicha falta es intencional o no» ( $\$ 110)$. La invocación de la Convención sobre la eliminación de todas las formas de discriminación contra la mujer (CEDAW) resulta sumamente importante en esta sentencia, máxime cuando de la misma se deriva que la prohibición de la violencia de género contra la mujer, como forma de discriminación, es un principio de derecho internacional consuetudinario. Esta categorización supone, aunque la sentencia no lo diga expresamente, que esta interdicción se aplica a la construcción de las obligaciones positivas del Estado ruso, independientemente de que haya o no ratificado el Convenio de Estambul.

Desde la perspectiva de análisis del art. $14 \mathrm{CEDH}$, el TEDH formula matices en el canon anteriormente expuesto respecto de la aplicación del art. $3 \mathrm{CEDH}$. El más importante tiene que ver con la obligación del Estado de justificar qué medidas correctivas de este fenómeno discriminatorio ha adoptado. Ya no se trata solo de evaluar si dentro de los parámetros previamente expuestos existe una legislación específica que proteja de la violencia doméstica. Se trata de que, constatada la discriminación estructural contra las mujeres y la existencia de violencia de género sistémica ${ }^{24}$, el Estado tiene la carga de justificar «qué tipo de medidas correctivas han adoptado las autoridades nacionales para corregir la desventaja asociada con el género y garantizar

23 Invocando el art. 1 de la CEDAW y la recomendación general núm. 35 (2017) del Comité CEDAW. Véase nota al pie 9.

24 La prueba prima facie, o prueba indiciaria de que tal discriminación concurre, viene dada, en este caso, por las estadísticas internacionales, los informes de las organizaciones de derechos humanos (internacionales o locales) o de la propia CEDAW. Y «una vez demostrada la existencia de un sesgo estructural en gran escala, como en los casos mencionados, la demandante no necesita demostrar que también fue víctima de un prejuicio individual. No obstante, si no hay pruebas suficientes que corroboren el carácter discriminatorio de la legislación y las prácticas o de sus efectos, se exigirá que se demuestre la parcialidad de cualquier funcionario que se ocupe del caso de la víctima para establecer una reclamación por discriminación» (\$114). 
que las mujeres puedan ejercer y disfrutar plenamente de todos los derechos humanos y libertades en igualdad de condiciones que los hombres» (\$111). Así, el Tribunal asume que el art. $14 \mathrm{CEDH}$ permite la adopción de medidas de acción positiva que permitan superar la discriminación fáctica reconocida y reconocible en perjuicio de las mujeres $(\$ 111)$. Y esta posibilidad se trasforma en obligación, vinculada al art. $14 \mathrm{CEDH}$ en relación con el art. $3 \mathrm{CEDH}$, cuando se trata de establecer medidas de control frente a la violencia intrafamiliar que sufren las mujeres.

En este asunto, el TEDH, recordando la naturaleza relacional del art. $14 \mathrm{CEDH}^{25}$, asume su aplicación al caso al haberse apreciado previamente que los hechos enjuiciados entraban en el ámbito de aplicación del art. 3 $\mathrm{CEDH}(\$ 115)$ y reconoce la existencia de un problema estructural en Rusia en relación con la violencia intrafamiliar de que son víctimas las mujeres (\$ 117-124). A partir de aquí, se produce la inversión de la carga de la prueba y surge la obligación del Estado de justificar si se han adoptado o no medidas de política orientadas al logro de una igualdad de género real, llegando el Tribunal a la conclusión de que no ha sido así y, por tanto, el Estado ha incurrido en vulneración del art. $14 \mathrm{CEDH}(\$ 132)$.

\section{LA PROSTITUCIÓN FORZOSA EN LA SENTENCIA DE LA GRAN SALA S. M. CONTRA CROACIA}

\section{LOS ANTECEDENTES JURISPRUDENCIALES SOBRE TRATA DE SERES HUMANOS EN EL MARCO DEL CONSEJO DE EUROPA}

La sentencia S. M. c. Croacia elige como marco de enjuiciamiento de la denuncia el mismo que había diseñado previamente el TEDH en materia de trata de seres humanos, lo cual provoca algunas distorsiones lógicas en la sentencia y muchas dificultades de análisis para los lectores de la misma. No obstante, asumiremos este presupuesto para avanzar en la reflexión.

La interdicción de trata de seres humanos y de explotación sexual forzosa aparece vinculada en la jurisprudencia de Estrasburgo al art. 4 CEDH, y el asunto S. M. c. Croacia se integra en esa línea jurisprudencial para ampliar el ámbito de aplicación de este precepto también en los casos de proxenetismo donde la coacción a la víctima no sea más que indiciaria.

La sentencia fundadora de la línea jurisprudencial enunciada es la STEDH Rantsev contra Chipre y Rusia, de 7 de enero de 2010, que parte de

25 Véase nota 6. 
la doctrina previa fijada en Siliadin contra Francia, de 26 de julio de 2005, en relación con la noción de servidumbre y de trabajo forzoso ${ }^{26}$. En el asunto Rantsev ${ }^{27}$, el padre de una joven rusa que había sido trasladada a Chipre, donde se la explotó sexualmente y sufrió una muerte violenta, instó al TEDH para que declarase que se había producido la vulneración de los arts. 2, 3, 4, 5 y 8 CEDH.

Aquel pronunciamiento identificó la trata de seres humanos, cuyos elementos clave define en los $\$ 281$ y 282 , como un supuesto de los prohibidos por el art. $4 \mathrm{CEDH}$, aunque no especificó cuál de los supuestos allí enunciados — «esclavitud», «servidumbre» $\mathrm{o}$ «trabajo forzoso u obligatorio»se identificaba con la trata. En cambio, sí se estableció que el concepto de trata asumido por el TEDH se ajustaba al marco jurídico internacional aplicable a la persecución de este tipo de delitos. A partir de estas premisas, asumiendo que los hechos denunciados eran constitutivos de un delito de trata y que resultaban exigibles las obligaciones positivas derivadas del art. $4 \mathrm{CEDH}^{28}$, se consideró que ni Rusia, país de origen de la mujer, ni Chipre, país en el que había sido explotada, habían respetado tales obligaciones ( $\$ 285$ y 286). Sin negar la importancia de Rantsev, la doctrina critica la falta de respuesta del pronunciamiento a las incertidumbres existentes sobre las formas de explotación, la interpretación que debe darse al consentimiento, la gravedad exigida a una explotación para considerarla trata o la importancia de la vulnerabilidad de la víctima en este contexto (Plouffe-Malette, 2020).

Tras Rantsev, la STEDH M. y otros contra Italia y Bulgaria, de 31 de julio de 2012, utiliza también el art. $4 \mathrm{CEDH}$ en un supuesto de matrimonio forzoso y posterior servidumbre de la mujer al marido para concluir, sin embargo, que no había pruebas suficientes de que la demandante fuera víctima de trata. A partir de ahí las sentencias sucesivas declaran hacer un intento por solventar las dudas que no abordó Rantsev, pero lo cierto es que distan de establecer una línea jurisprudencial unívoca, clara y definitiva.

26 La STEDH Silaidin c. Francia define la servidumbre como una obligación, bajo coacción, para brindar determinados servicios, estando vinculada al concepto de esclavitud ( $\$ 124)$. Mientras que el trabajo forzoso exige que la prestación del servicio se realice en un contexto en que exista alguna limitación física o mental, así como algún condicionante de la voluntad de la persona $(\$ 117)$. Para profundizar en este asunto véase Castro Sánchez (2005).

27 Trata en profundidad el contenido y alcance de esta sentencia Serra Cristóbal (2015).

28 Estas obligaciones son sintetizadas por algunos autores como las «tres P»: obligación de prevención, obligación de protección y obligación de persecución (Plouffe-Malette, 2020). 
En la STEDH C. N. y V. contra Francia, de 11 de octubre de 2012, se confirma la distinción establecida en Silaidin entre servidumbre y trabajo forzoso, reforzándola al especificarse que la servidumbre, como forma cualificada de trabajo forzoso, se identifica en la sensación de las víctimas de que su condición es inmutable y la situación no es susceptible de cambio ${ }^{29}$. En la sucesiva STEDH C. N. contra Reino Unido, de 13 de noviembre de 2012, el Tribunal insiste en la noción de servidumbre, y detalla algunos elementos de la obligación positiva de investigar las denuncias sobre comportamientos que pudieran calificarse como tal ${ }^{30}$.

En la STEDH J. y otros contra Austria, de 17 de enero de 2017, pese a terminar desestimando la demanda, el Tribunal intenta distinguir los conceptos de trata y trabajo forzoso, de las nociones de esclavitud y servidumbre. Así, afirma que «el trabajo forzado no siempre es lo mismo que la trata, y la trata no siempre es lo mismo que la esclavitud. Estas dos amalgamas deben evitarse como manifestaciones de lo que se ha descrito como el "mal uso de la explotación" [...]. Dado que la trata es una fase preparatoria para la futura explotación, está vinculada a cada una de las tres prácticas prohibidas por el artículo 4. Pero la trata de personas no implica necesariamente una explotación posterior y puede existir explotación sin que haya habido trata de persona» $(\$ 130)$. En suma, la sentencia define la trata como una fase preparatoria de la explotación laboral, la esclavitud o la servidumbre, desconectando la finalidad —que con el acto y los medios son parte integrante de la configuración

29 «\$91. En este caso, el elemento fundamental que distingue la servidumbre del trabajo forzoso u obligatorio, en el sentido del artículo 4 del Convenio, es el sentimiento de las víctimas de que su condición es inmutable y de que la situación no es susceptible de cambio. A este respecto, basta con que este sentimiento se base en elementos objetivos creados o mantenidos por los autores de los hechos».

30 « 69. La obligación de investigar no depende de una denuncia de la víctima o de los familiares: una vez que el asunto ha llegado a conocimiento de las autoridades, estas deben actuar de oficio [...]. Para que una investigación sea eficaz, debe ser independiente de los implicados en los hechos. También debe ser capaz de conducir a la identificación y el castigo de los individuos responsables, una obligación no de resultado sino de medios. En todos los casos está implícita la exigencia de celeridad y rapidez razonable, pero cuando exista la posibilidad de apartar al individuo de la situación perjudicial, la investigación debe emprenderse con carácter de urgencia. La víctima o los familiares deben participar en el procedimiento en la medida necesaria para salvaguardar sus intereses legítimos $[\ldots] »$. 
del delito de trata ${ }^{31}$ - del concepto de trata empleado por Estrasburgo, lo que supone una desvinculación que en Rantsev no parecía posible.

Por su parte, en Chowdury y otros contra Grecia, de 30 de marzo de 2017, se aborda el tema de la explotación laboral, en este caso de 42 bangladesíes que fueron empleados en la recolección de la fresa. Aunque considera aplicable al caso el canon del art. $4 \mathrm{CEDH}$, la sentencia no distingue entre las nociones de trabajo forzado y trata de seres humanos para la explotación laboral, pero en cambio realiza una reflexión sumamente interesante sobre la irrelevancia del consentimiento previo de la víctima en determinados supuestos. Así, afirma que "cuando un empleador abusa de su poder o toma ventaja de la vulnerabilidad de sus trabajadores con el fin de explotarles, los trabajadores no se prestan voluntariamente al trabajo. El consentimiento previo de la víctima no es suficiente para excluir la calificación de trabajo forzoso. La cuestión del ofrecimiento individual de manera voluntaria para trabajar debe ser examinada a la luz de todas las circunstancias concurrentes al caso" ( $(95)$.

Por lo que hace a la explotación sexual, y siempre tomando como referencia jurisprudencial Rantsev, la STEDH L. E. contra Grecia, de 21 de enero de 2016, va perfilando las obligaciones positivas del Estado en el marco de la lucha contra la trata y la explotación sexual de las mujeres (Stoyanova, 2016). Por último, en T. I y otros contra Grecia, de 18 de julio de 2019, se califica la situación de explotación sexual como trata para aplicar el art. 4 $\mathrm{CEDH}$, pero sin aclarar por qué en este supuesto se considera que existe trata de seres humanos y no prostitución forzosa, por ejemplo, y sin abrir específicamente el art. $4 \mathrm{CEDH}$ a esta última.

Es suma, en la jurisprudencia previa ${ }^{32}$ el Tribunal considera que la explotación laboral o sexual de cierta entidad deben ser tratadas bajo la perspectiva

31 Así se contempla en el art. 3 del Protocolo de las Naciones Unidas para Prevenir, Reprimir y Sancionar la Trata de Personas, Especialmente Mujeres y Niños (también conocido como el Protocolo contra la Trata de Personas o Protocolo de Palermo). El texto, aprobado en el año 2000, es un protocolo a la Convención de las Naciones Unidas contra la Delincuencia Organizada Transnacional.

32 No trato en el texto, deliberadamente, la STEDH V. T. c. Francia, de 11 de diciembre de 2007, puesto que plantea el problema desde una perspectiva totalmente diversa. En aquel caso la requirente pretendía abandonar la prostitución, a la que decía venirse dedicando de forma voluntaria, y la Administración, cuando se inscribe en el sistema ordinario de profesionales liberales de la seguridad social, le reclama deudas de diversa índole, forzándola de este modo, según la demandante, a continuar prostituyéndose. En este supuesto el TEDH sostiene que este rechazo no puede ser considerado como un trato inhumano o degradante ex art. $3 \mathrm{CEDH}$, ni la avoca a la servidumbre prohibida por el art. 4 CEDH. A mi juicio, el tratamiento del problema no encaja con lo 
del art. $4 \mathrm{CEDH}$, sin necesidad de catalogarlas como esclavitud, servidumbre o trabajo forzoso, pero no aclara cuáles son las modalidades de explotación afectadas por el precepto, cuando debe entenderse que existe trata o cuando mera explotación laboral (o sexual) sin las condiciones que exige la trata de seres humanos, y en qué supuestos el consentimiento de las víctimas - más allá de lo expuesto en la STEDH Chowdury y otros c. Grecia- puede o no tener relevancia al definir las obligaciones positivas de los Estados.

De modo que llegaremos a la sentencia de Sección de S. M. c. Croacia, de 19 de julio de 2018 sin resolver todas estas dudas, y el Tribunal optará por ampliar el ámbito de protección del art. $4 \mathrm{CEDH}$ a la explotación sexual sea o no sea trata, obligando a la Gran Sala, en su sentencia posterior de 25 de junio de 2020, a retomar el asunto para aclarar esta extensión jurisprudencial.

\section{EL SUPUESTO DE HECHO EN LA STEDH GRAN SALA S. M. CONTRA CROACIA}

La recurrente, S. M., nació en el año 1990. Vivió en acogimiento familiar entre el año 2000 y el año 2004 debido a problemas familiares. Posteriormente lo hizo en una institución pública hasta que finalizó su formación profesional en el sector de la restauración. Tras ello se fue a vivir con su padre, visitando ocasionalmente a su madre.

Durante la primavera de 2011 se puso en contacto con ella a través de una red social un varón que decía ser amigo de sus padres. Esta relación se mantuvo unas semanas hasta que se encontraron físicamente y el hombre, T. M., le propuso continuar en contacto porque podía ayudarla a conseguir trabajo. En un segundo encuentro, acontecido en junio o julio, T. M. informó a S. M. de que la llevaría a casa de un hombre al que prestaría servicios sexuales remunerados, por los que se le abonarían el equivalente a cincuenta euros que debía dividir con él. Ella, temiendo contradecirle, le acompañó, aunque no prestó servicio alguno, razón que llevó a T. M. a golpearla, exigiéndole obediencia a sus instrucciones. Posteriormente S. M. cedió a las pretensiones de T. M., quien terminó por proporcionarle un móvil y alquilar un apartamento para que prestase allí sus servicios manteniéndola bajo control.

En septiembre de 2011, aprovechando la ausencia de T. M., la señora S. M. huyó a casa de una amiga, a quien explicó la situación que estaba viviendo. Tras ello, T. M. contactó de nuevo por las redes sociales para pedirle que volviera con él, y pasó a amenazarla a ella y a su familia ante la ausencia de

abordado en el presente trabajo, pese a que varios obiter dicta de la sentencia podrían resultar interesantes. 
respuesta. Poco a poco el hostigamiento cesó, hasta un año más tarde, en que se reestableció el contacto con amenazas veladas a su familia. Temiendo por la seguridad de sus allegados, S. M. se decide a presentar una denuncia ante la policía el 27 de septiembre de 2012.

La denuncia abre una investigación preliminar en la que se produce la entrada y registro domiciliario en casa de T. M. el 10 de octubre de 2012, donde se encuentran armas de fuego y diversos teléfonos móviles. En esta investigación preliminar se constata también la existencia de antecedentes policiales y penales por proxenetismo bajo coacción y violación (art. 195.2 y 3 y art. 188.1 CP Croata), por lo que había sido condenado por estas causas a seis ańos y medio de privación de libertad. Tras el interrogatorio del denunciado, se insta apertura de proceso penal al considerar los hechos constitutivos del tipo contemplado en el art. 195.3 CP Croata, es decir, proxenetismo bajo coacción. El juez de instrucción ordena la prisión provisional de T. M., que se mantendrá hasta el final del procedimiento

En la instrucción penal, tras tomar declaración a T. M. y a S. M., se llama como testigo a la amiga de S. M. en cuya casa se refugió en septiembre de 2011 y se levanta acta de acusación contra T. M., confirmada el 22 de noviembre de 2012, por proxenetismo bajo coacción (art. 195.3 CP). La prueba de cargo principal era la declaración de la víctima corroborada por la de la testigo de la acusación.

El 21 de diciembre de 2012, la oficina de derechos humanos y de los derechos de las minorías de la República de Croacia, reconoció a la denunciante el estatuto de víctima de trata de seres humanos, beneficiándose en tanto que tal de la asistencia de la Cruz Roja, que le proporcionó acompańamiento psicosocial con un seguimiento individualizado y alguna ayuda material. Simultáneamente, el Centro Rosa le proporcionó asistencia jurídica.

En el proceso oral (desarrollado entre el 12 de diciembre de 2012 y el 15 de febrero de 2013), se interroga de nuevo a denunciante y denunciado, así como a la testigo de referencia, concluyéndose que, si bien T. M. organizó una red de prostitución a la que incorporó a la denunciante, no habría quedado probado que se hubiera forzado a esta a prostituirse ni que se hubiera ejercicio sobre ella ninguna presión, siendo este un elemento clave de la infracción contenida en el art. 195.3 CP croata. La sentencia niega la posibilidad de atribuir un peso mayor a la declaración de la víctima porque esta era incoherente y contradictoria en ocasiones con la testifical, lo que restaba veracidad a su testimonio. La resolución absolutoria fue confirmada en apelación el 21 de enero de 2014.

Antes de que se resolviese la apelación, el Centro Rosa planteó una reclamación a la Oficina de Derechos Humanos al considerar que el juez de la instancia penal no había actuado con diligencia en el proceso interesado por 
la denunciante, particularmente a la hora de completar el acervo probatorio que habría permitido esclarecer los hechos. Ya en este momento se plantea la eventualidad de que el juzgado hubiera podido recalificar los hechos a una infracción simple de proxenetismo (sin coacción), lo que hubiera permitido condenar a M. T., en virtud de los hechos declarados probados, por el tipo contenido en el art. 195.2 CP Croata. Tras la oportuna tramitación de la queja y la emisión de los informes judiciales pertinentes se concluye que el órgano juzgador podría, efectivamente, haber modificado la calificación de los hechos, pero no se abre vía procesal alguna para revisar la decisión judicial.

La recurrente acude al Tribunal Constitucional contestando el modo en que se habían aplicado a su caso los mecanismos de derecho penal previstos en el ordenamiento, pero el TC inadmite el 10 de junio de 2014 la demanda bajo el argumento de que, al tratarse de un proceso penal, el único legitimado para recurrir habría sido el procesado.

\section{EL CANON DESARROLLADO POR LA GRAN SALA: LA EXPLOTACIÓN FORZOSA DE LA PROSTITUCIÓN AJENA COMO SITUACIÓN PROHIBIDA POR EL ART. 4 CEDH}

La demanda ante el TEDH fue presentada el 27 de agosto de 2014, invocándose la vulneración de los arts. 3, 6 y $8 \mathrm{CEDH}$ porque las autoridades croatas no habrían aplicado de manera efectiva los mecanismos de derecho penal pertinentes en respuesta a sus denuncias de trata de seres humanos y/o de explotación de la prostitución ajena.

En la sentencia de Sección, el TEDH se centra en el art. $4 \mathrm{CEDH}$, siendo esta redefinición del objeto blanco de una dura crítica de la juez Koskelo en el voto particular a este primer pronunciamiento ${ }^{33}$. La sentencia

33 El voto sostiene literalmente que «en el presente caso, la demandante planteó su reclamación en virtud de los artículos 3, 6 y 8 (pero no del artículo 4). La base fáctica en la que se basaba era la alegación de que T. M., a quien la demandante acusaba de coaccionarla para que ejerciera la prostitución, no había sido condenado por los tribunales nacionales, aunque los tribunales habían establecido que se habían probado los elementos de una forma menos grave del delito penal denunciado, a saber, el delito de proxenetismo (en el que el autor no utiliza la fuerza) [...] En el presente caso, la mayoría se encargó de abordar y pronunciarse sobre cuestiones a las que la demandante no había hecho ninguna referencia en su solicitud, ni siquiera en sus alegaciones posteriores ante el Tribunal. En particular, la demandante no se quejó de ninguna deficiencia en la investigación, ni mencionó ninguna deficiencia en la recopilación de pruebas por parte de las autoridades nacionales, ni mencionó ninguna posible omisión relativa a testigos adicionales». 
de sección resulta estimatoria, y pese a las alegaciones del Estado croata, que insta el conocimiento del asunto por la Gran Sala, esta mantiene la definición del objeto del recurso formulada en Sección (STEDH Gran Sala S. M. c. Croacia, $\$ 229)^{34}$.

La Gran Sala retoma en gran medida el pronunciamiento de la Sección, apoyándose sobre la jurisprudencia previa y confirmando las obligaciones positivas que se imponen a los Estados en el marco del art. $4 \mathrm{CEDH}$, esto es:

- Tipificar en la ley nacional los comportamientos vinculados a la aplicación del art. 4 CEDH.

- Llevar a cabo una investigación penal eficaz cuando haya motivos razonables para creer que pudo cometerse un delito vinculado a situaciones prohibidas por el art. $4 \mathrm{CEDH}$. Sobre esta obligación procesal, la sentencia desarrolla las siguientes especificaciones:

a. Es preciso abrir y proseguir la investigación de forma efectiva desde que haya denuncia o indicios suficientes $(\$ 313)$.

b. Es necesario actuar de oficio cuando un asunto se haya sometido a la atención de las autoridades, siempre que ello no suponga una carga excesiva (\$314).

c. Deben adoptarse medidas de investigación razonables para obtener pruebas y clarificar la denuncia $(\$ 316)$.

d. Y a la hora de valorar si hay fallos importantes en el proceso es preciso analizar $(\$ 329)$ : si ha existido pronta respuesta; si la víctima pertenece a una categoría vulnerable; si el modus operandi descrito corresponde con el proceso de captación o explotación; si el denunciado

34 No puede obviarse el hecho de que existen dudas notables sobre la definición del objeto del procedimiento que contaminan los indudables avances jurisprudenciales que proporciona la sentencia. Y es que una parte de la queja inicial de la recurrente, como se verá en el apartado siguiente, se refiere a la subsunción de los hechos denunciados en el marco de la legislación croata y al hecho de que se absolviera al denunciado por prostitución forzosa y no se le condenara por proxenetismo existiendo prueba suficiente para ello. La misma prueba, por cierto, que el Tribunal empleará en la sentencia para considerar la concurrencia de indicios de que existió coacción sobre la víctima para ejercer la prostitución. A pesar de estos condicionantes iniciales, el TEDH reconduce todas las quejas a la lesión del art. $4 \mathrm{CEDH}$ por falta de investigación bastante, desde el presupuesto de que había esos indicios de coacción, y por tanto era aplicable el art. 4 CEDH. También la jueza Síofra O’Leary y el juez Georges Ravarani ponen de manifiesto esta reconstrucción del objeto en sus votos particulares a la sentencia de la Gran Sala. 
está en posición de fuerza objetiva sobre la víctima; si se ha acudido a elementos de prueba suficientes ${ }^{35}$.

- Adoptar medidas de protección cuando exista un riesgo, real e inmediato, de que una persona sea sometida a una de las situaciones que se regulan en el art. 4 CEDH.

- Desarrollar un cuadro reglamentario eficaz de prevención frente a las situaciones previstas en el art. $4 \mathrm{CEDH}^{36}$, y

Ahora bien, el problema más relevante que plantea la sentencia no es la configuración de las obligaciones positivas derivadas del art. $4 \mathrm{CEDH}$, sino la justificación de por qué el proxenetismo (al menos el coactivo) también se considera actividad prohibida por este precepto, generándose en relación con las obligaciones positivas descritas.

En este caso, derivada del propio procedimiento interno, existe una clara indefinición sobre la situación vivida por la víctima, y resulta complicado identificar si fue víctima de trata (así se la reconoce administrativamente), si fue víctima de prostitución forzosa (así lo alega ella) o fue parte de una red de prostitución en beneficio de un tercero de forma voluntaria (es lo que se deduciría de los hechos probados en la instancia). Esta dificultad podría haber dado pie al Tribunal para aclarar la diferencia entre los tres tipos de situaciones y para especificar cuál de ellas permite a las mujeres invocar la aplicación del art. 4 CEDH. Pero lo cierto es que la clarificación conceptual no va a producirse, limitándose el Tribunal a considerar que, ante los indicios existentes, en este caso el precepto en liza resultaba de aplicación.

La sentencia de Sección sí es más clara, y proyectaba la doctrina sobre la trata de seres humanos a la explotación de la prostitución en los siguientes términos:

$\$ 54$. [...] Teniendo en cuenta su obligación de interpretar el Convenio a la luz de las condiciones de vida actuales, el Tribunal considera que no es necesario determinar si el trato en cuestión equivale a «esclavitud», «servidumbre» o «trabajo

35 En el voto concurrente a la sentencia de la jueza Ksenija Turković se pone de manifiesto que la Gran Sala no aplica el canon completo porque se limita a valorar la investigación policial sin adentrarse en lo sucedido durante el proceso judicial.

En este caso no me detengo en el contenido específico de las obligaciones positivas, sin negar su interés, porque me parece más relevante la cuestión relativa a la proyección de esas obligaciones sobre la prostitución forzada e, incluso, sobre la prostitución voluntaria. En todo caso se recomienda la lectura de $\$ 304$ a 320 de la sentencia, al objeto de conocer en detalle las obligaciones positivas que incumben a los Estados en materia de lucha contra la trata de seres humanos y contra la prostitución forzosa. 
forzoso u obligatorio». Por el contrario, concluye que la trata de seres humanos, así como la explotación de la prostitución, en el sentido del artículo 3.a del Protocolo de Palermo, del artículo 4.a del Convenio del Consejo de Europa contra la Trata de Personas y el artículo 1 del Convenio para la Represión de la Trata de Personas y de la Explotación de la Prostitución Ajena y de la CEDAW [...] están comprendidos en el ámbito de aplicación del artículo 4 del Convenio, por lo que examinará el presente caso con arreglo a dicha disposición. A este respecto, es irrelevante que la demandante sea de hecho nacional del Estado demandado y que el caso no tenga ningún elemento internacional, ya que el artículo 2 del Convenio contra la trata de seres humanos se aplica a «todas las formas de trata de seres humanos, ya sean nacionales o transnacionales» [...] y el Convenio para la represión de la trata de personas y de la explotación de la prostitución ajena se refiere a la explotación de la prostitución en general [...].

Por tanto, según la Sección, la explotación de la prostitución, esto es, el proxenetismo, queda prohibido a la luz del art. $4 \mathrm{CEDH}$. Consciente de la innovación que la Sala introduce en la doctrina previa con estas apreciaciones, la Gran Sala afirma la necesidad de revisar el contenido del parágrafo transcrito especificando el ámbito de aplicación material del art. $4 \mathrm{CEDH}$ (\$277). Y lo hace evitando aclarar conceptualmente las diferencias entre trata, explotación de la prostitución y trabajo forzoso, y resolviendo el caso concreto en virtud de las circunstancias en presencia.

Así, la sentencia establece lo siguiente:

- El art. $4 \mathrm{CEDH}$ se aplica a los supuestos de trata de seres humanos, en cuanto esta se vincula a las nociones de servidumbre, esclavitud y trabajos forzosos. Para que se entienda concurrente una situación de trata es preciso que se den los elementos constitutivos de la definición internacional de trata tal y como se contienen en el Protocolo de Palermo ${ }^{37}$ y en el Convenio de Varsovia ${ }^{38}$ respecto de los actos, los medios y el objetivo de las actividades cuestionadas. Por lo que hace al ámbito de aplicación de la noción de trata, la definición que asume el TEDH es la que se contiene en el Convenio de Varsovia, que prevé un ámbito

37 Protocolo para prevenir, reprimir y sancionar la trata de personas, especialmente mujeres y niños, que complementa la Convención de las Naciones Unidas contra la Delincuencia Organizada Transnacional, hecho en Nueva York el 15 de noviembre de 2000.

38 Convenio del Consejo de Europa sobre la Lucha contra la Trata de Seres Humanos (Convenio n. ${ }^{\circ} 197$ del Consejo de Europa), hecho en Varsovia el 16 de mayo de 2005. 
de aplicación más amplio que el Protocolo de Palermo, considerando trata también la que carece del elemento transnacional, así como las situaciones en las que no existe un grupo criminal organizado implicado $(\$ 295-297)^{39}$. Resulta igualmente de interés poner de manifiesto que la sentencia afirma que el reconocimiento administrativo de la condición de víctima potencial de la trata no puede considerarse como la confirmación de que se han detectado los elementos constitutivos del delito de trata de seres humanos $(\$ 322)^{40}$.

- El art. $4 \mathrm{CEDH}$ se puede aplicar también a los supuestos de prostitución forzada o de explotación coactiva de la prostitución ajena. A este respecto la sentencia evita pronunciarse sobre si la explotación de la prostitución ajena debe ser o no considerada trata de seres humanos e insiste en que «el hecho de que una situación determinada reúna todos los elementos de la "trata de seres humanos" (acto, medios, finalidad) y/o plantee un problema concreto de prostitución forzada es una cuestión de hecho que debe examinarse a la luz de todas las circunstancias pertinentes del caso en cuestión» (\$302). A pesar de lo anterior, establece que también estos supuestos de explotación sexual forzosa (sean o no trata) se sitúan bajo la protección de las previsiones del art. $4 \mathrm{CEDH}$. Se dice literalmente que el "concepto de "trabajo forzoso u obligatorio" en el sentido de esta disposición tiene por objeto ofrecer protección contra los casos de explotación grave, como los casos de prostitución forzada [...]. Además, esta conducta puede tener elementos que la califiquen como "servidumbre" o "esclavitud" en el sentido del artículo 4, o plantear un problema en virtud de otra disposición del Convenio» ( $\$ 300)$. Así pues, la prostitución forzosa se distingue de la trata, aunque el Tribunal no nos dice en qué, y puede estar vinculada, como la trata, al trabajo forzoso, a la servidumbre o a la esclavitud.

En suma, la sentencia, pese a la declarada pretensión de clarificar conceptos, se limita a considerar aplicable el art. $4 \mathrm{CEDH}$ tanto a los supuestos de prostitución forzosa como a los supuestos de trata, sea cual sea la diferencia entre una y otra noción e independientemente de la gravedad de la conducta identificada. El problema ahora se sitúa, por tanto, en otro lado. Concretamente, en el que exige identificar a una mujer como víctima potencial de trata o de prostitución forzosa. Y si bien la identificación de las

39 A este respecto resulta de interés atender a la crítica de Stoyanova (2017: 41).

40 Sobre la ambigüedad de la definición de trata de seres humanos en la jurisprudencia del TEDH véase Stoyanova (2017). 
víctimas de trata responde a criterios más elaborados por el derecho penal internacional y el derecho internacional de los derechos humanos, no sucede lo mismo con la identificación de las víctimas de prostitución forzosa que, en no pocas ocasiones, pueden llegar a confundirse con las mujeres que consienten en prestar servicios sexuales a cambio de dinero. Estamos, frente a frente, ante la cuestión del consentimiento, que puede permitirnos avanzar sobre la identificación de la coacción o la fuerza, por parte del proxeneta. Pero el TEDH no se detiene aquí. Se queda en los márgenes del problema y nos habla de la suficiencia de los indicios a la hora de considerar aplicable el art. 4 $\mathrm{CEDH}$. Indicios que pueden ser, indistintamente, sospechas de que la mujer es víctima de trata o de prostitución forzosa.

En este sentido, la sentencia afirma que, a la hora de establecer si se dan las circunstancias para calificar la situación vivida por la denunciante como trata o como explotación forzosa, a los efectos de aplicar el art. $4 \mathrm{CEDH}$ en su vertiente procesal (obligación de investigar) basta con que se aporte prueba indiciaria por la víctima, lo mismo que se exige para aplicar el art. $3 \mathrm{CEDH}^{41}$, sin que el TEDH quede condicionado por las conclusiones extraídas por las autoridades judiciales nacionales $(\$ 325)^{42}$.

Sin embargo, el Tribunal se muestra poco claro sobre cuáles son los elementos indiciarios de que se está produciendo prostitución forzosa, limitándose a establecer que la fuerza o coacción puede abarcar formas sutiles de comportamiento coercitivo. La sentencia afirma que existían indicios de que la demandante "pertenecía a una categoría vulnerable [...], mientras que la posición y los antecedentes de T.M. tienden a indicar que él estaba en condiciones de ejercer dominio sobre ella y de abusar de su vulnerabilidad con la finalidad de la explotación a través de la prostitución [...]. También hay que señalar que las alegaciones y circunstancias anteriores, que sugieren en particular que T. M. ganaba dinero ilegalmente de los servicios sexuales prestados por la demandante, en un contexto en el que es concebible que ejerciera dominación sobre ella y utilizara la fuerza, las amenazas y otras formas de coacción dan lugar en cualquier caso a una alegación discutible de prostitución forzada y a una prueba prima facie de dicho trato, que está

41 En el voto concurrente que firman la jueza Síofra O’Leary y el juez Georges Ravarani se pone en duda que sea posible trasladar el canon desarrollado para los arts. 2 y 3 $\mathrm{CEDH}$, en el sentido descrito en el texto, al art. $4 \mathrm{CEDH}$.

42 El magistrado Georgios A. Serghides centra su voto en esta cuestión para poner en duda la necesidad de entrar a la distinción conceptual entre trata y prostitución forzosa. A su juicio hubiera bastado con calificar los hechos como prestación forzosa por parte de la víctima para no entrar a la cuestión de la distinción entre prostitución forzosa y trata que, en cualquier caso, la sentencia no acaba de resolver. 
en sí mismo prohibido por el artículo 4 del Convenio» ( $\$ 329$ y 331). Dicho en otros términos, el TEDH considera bastante la prueba indiciaria de que pudo existir explotación porque se daban las circunstancias favorables para ello, independientemente del eventual consentimiento de la víctima, y sin que importe que esos indicios lleven o no a considerar los hechos como propios de la trata de seres humanos o de la prostitución forzosa. Esas razones le llevan a considerar vulnerado el art. $4 \mathrm{CEDH}$, al entender que el Estado croata no ha respondido a las obligaciones positivas que se derivan del precepto $y$, muy concretamente, a las obligaciones procesales de investigación y de procesamiento de las personas acusadas de estos graves delitos.

Al centrarse en la noción de fuerza y en la existencia de indicios a este respecto, el Tribunal ignora la importancia del consentimiento ${ }^{43}$, a pesar de que la ausencia de este es utilizada en la propia sentencia para definir el trabajo forzoso, que también queda prohibido por el art. $4 \mathrm{CEDH}$. Como el Tribunal obvia la calificación expresa de los hechos, no puede descartarse la aplicación del canon establecido a supuestos de prostitución voluntaria cuando un tercero obtenga beneficios de ello, es decir, cuando exista un proxeneta y concurran los indicios arriba apuntados. De hecho, en la legislación croata también se persigue el proxenetismo cuando no se ejerce la fuerza y uno de los argumentos de la reclamación de la demandante se refería, precisamente, a la ausencia de recalificación de los hechos para que T. M. fuera al menos

43 En el voto concurrente del magistrado Pere Pastor Vilanova, este critica abiertamente la ambigüedad de la Gran Sala, afirmándose que la jurisprudencia previa «para caracterizar el trabajo forzoso, el Tribunal ha exigido efectivamente la presencia de una amenaza, pero también la ausencia de un verdadero consentimiento al mismo. Sin embargo, este último elemento parece estar excluido o, al menos, muy minimizado en el presente caso, ya que la Gran Sala se centra en la noción de fuerza. [...]. Sin embargo, ha llegado el momento de decidir si, como tal, la explotación de la prostitución por otros sigue siendo compatible con el Convenio Europeo de Derechos Humanos. No lo creo como regla general. La dignidad humana no se puede pagar. El principio de no patrimonialidad del cuerpo humano también sigue siendo incompatible con su mercantilización (res extra commercium) e inadecuado para la figura del contrato de trabajo. [...]. En mi opinión, la explotación de la prostitución, tal y como se define en el apartado 117 de la sentencia, es decir, la obtención ilícita de un beneficio económico o de otro tipo a partir de la prostitución ajena, debe presumirse contraria al artículo 4 del Convenio. La única excepción es la prostitución consentida libre, consciente y explícitamente, que no puede calificarse de trabajo forzoso. Por tanto, todas las demás formas de prostitución no consentida entran en el ámbito de aplicación del artículo 4. [...] En mi opinión, la prostitución consentida sólo puede considerarse libre e informada si, y sólo si, el consentimiento se formula y se obtiene de forma indiscutible». 
condenado por esta actividad lucrativa. Pero el Tribunal no se pronuncia a este respecto desde el momento en que considera plausible la existencia de fuerza o coacción en este caso.

Algunas críticas afirman que, de la falta de concreción de la sentencia, podría llegar a deducirse una postura abolicionista del TEDH que asumiría, de ser cierto y siempre según estas voces críticas, una postura que no es objeto de consenso ni en el derecho internacional ni en el derecho interno de los países del Consejo de Europa (Trujillo del Arco, 2020 ${ }^{44}$ ). Donde Volodina nos habla de ius cogens en materia de violencia de género en el ámbito de la pareja, S. M. no puede acudir al mismo consenso internacional, aunque lo intente (\$293). No obstante, esta posición crítica no es unánime. Otras autoras entienden que la posición ambigua de la Corte es defendible porque «evita acertadamente tomar parte en el debate sobre el reconocimiento de la prostitución como trabajo, pero sigue condenando los actos de explotación y, por tanto, la prostitución forzada» (Plouffe-Malette, 2020: 436) ${ }^{45}$.

\section{LAS LUCES Y LAS SOMBRAS DE UNA JURISPRUDENCIA EVOLUTIVA: LA DIFICULTAD DE DEFINIR CONSENTIMIENTO Y RIESGO}

Los dos pronunciamientos guardan algunas similitudes que merecen ser destacadas desde una valoración crítica positiva.

Ambos ponen de manifiesto la importancia del litigio estratégico en temas relacionados con la agenda feminista, así como la relevancia del trabajo en red de las organizaciones de la sociedad civil ${ }^{46}$.

44 Esta autora cifra su crítica en la cita que hace la sentencia del art. 1 de la Convención de 1949, tras un examen detallado de la regulación internacional de todo el siglo xx en materia de trata y persecución de la explotación sexual. A juicio de Trujillo, la invocación de un documento de corte abolicionista, sin mayores explicaciones, pondría de manifiesto un sesgo en el pronunciamiento del Tribunal, que también se deduciría de la amalgama entre los conceptos de trata y prostitución forzosa. A mi juicio, esta apreciación obvia la ambigüedad manifiesta de la sentencia a la hora de formular conceptos y definiciones claras sobre la materia y no parece sencillo deducir el sesgo denunciado de la sentencia con la mera lectura de esta y sus votos concurrentes.

45 Traducción propia.

46 En el caso Volodina la recurrente está representada por una ONG holandesa [Stichting Justice Initiative (srji.org)] e interviene como amicus curiae una asociación inglesa (Equal Rights Trust), mientras que en el caso $S$. $M$. la recurrente está representada por una organización croata (Centro ROSA), participando como amicus curiae, con 
En las dos sentencias tiene notable importancia el relato sobre el contexto y sobre la cultura jurídica, aunque quizá sea más relevante en el caso de Volodina (véanse $\$ 40-44$ y $\$ 61-66$ ). Y en ese relato, de nuevo, vale la pena resaltar la presencia de informes de organizaciones de la sociedad civil.

También en ambos supuestos destaca sobremanera la importancia de los documentos internacionales a la hora de construir el contenido de los preceptos del CEDH, siendo particularmente intensa la cita de documentos internacionales en el caso $S$. $M$. (véanse $\$ 95-212$ ). Resulta relevante asimismo el valor interpretativo concedido a la soft law jurisprudence, es decir, a las resoluciones de los órganos de tratados (como por ejemplo el Comité CEDAW). A pesar de esta valoración positiva, no puede ocultarse el hecho de que sobre el tema de la prostitución en concreto no existe acuerdo internacional y, por tanto, la invocación de las fuentes citadas puede resultar intrínsecamente contradictoria, lo que hace de la exposición de la sentencia una descripción compleja cuyo objetivo final se nos escapa. Frente a ello, parece claro que el TEDH asume la existencia de un ius cogens internacional en relación con la violencia de género en el ámbito de las relaciones de pareja.

Las dos sentencias se inscriben en una línea de jurisprudencia evolutiva y con perspectiva de género. Las dos insisten en que la violencia de género (en las dos formas que abordan los asuntos) constituye una vulneración clara de la igualdad entre hombres y mujeres en perjuicio de estas últimas. Y también las dos construyen una serie de obligaciones de los Estados, que podríamos traducir en exigencias de desarrollar acciones afirmativas destinadas a marcar las políticas públicas de estos en materia de lucha contra la violencia de género. Estamos ante la definición de un estándar mínimo común en este ámbito.

Junto a lo anterior, también se identifican en ambos pronunciamientos, pero particularmente en S.M. c. Croacia, algunas debilidades a las que ya se ha hecho referencia, pero que merece la pena destacar sintetizándolas con el objetivo de poner de manifiesto en qué puntos debiera reforzarse la jurisprudencia de Estrasburgo de cara al futuro.

La STEDH Volodina c. Rusia adolece de indefinición del concepto de riesgo para las víctimas. Un elemento que, de constatarse, exigiría al Estado actuar de manera preventiva. La propia sentencia reconoce que esta obligación supone una injerencia de las autoridades en la vida privada y familiar que puede justificarse por la necesidad de proteger la salud o los derechos de la víctima

posiciones sumamente interesantes la Clínica Doctoral de Derecho Internacional de Derechos Humanos de la Facultad de Derecho de Aix en Provence, el equipo L' Altro Diritto ONLUS (Universidad de Florencia) y un grupo de investigadores de distintas universidades europeas. 
( $\$ 86)$, pero no acaba de definir claramente en qué supuestos la intervención es necesaria porque el riesgo es real e inminente. Quizá la consideración de la inminencia o inmediatez del riesgo no sea una aproximación adecuada cuando hablamos de violencia de género, aunque pueda funcionar con otros tipos de violencia, tal y como sugiere en su voto particular el juez Pinto de Alburquerque $^{47}$. En cualquier caso, el Tribunal está muy lejos de formular una definición precisa de riesgo o de establecer un canon o un método que permita identificar ese riesgo a las autoridades nacionales, sean estas de los cuerpos policiales, sean miembros del poder judicial ${ }^{48}$.

Una crítica similar merece S.M. c. Croacia, pero, en este caso, en relación con el concepto de consentimiento, al que cita, pero después no le da ninguna relevancia a la hora de considerar los indicios que fuerzan la actuación del estado en virtud de la vertiente procesal de art. $4 \mathrm{CEDH}$.

A juicio de Trujillo (2020), el problema es que el TEDH al hablar del consentimiento equipara en esta sentencia dos estándares internacionales que no pueden formularse como equivalentes, y lo hace cuando se refiere - muy superficialmente- a la irrelevancia del consentimiento de las víctimas. Según esta autora, en el Protocolo de Palermo ${ }^{49}$ y en el Convenio de Varsovia el consentimiento es irrelevante porque está viciado en los supuestos de trata.

47 Recuérdese el contenido de la nota al pie 14.

48 En este sentido podría servir de guía o modelo el sistema español, que prevé una diligencia de valoración del riesgo de violencia de género en el art. 282 LECrim, tras la reforma en él introducida por la Ley del Estatuto de la Víctima del Delito (Ley 4/2015, de 27 de abril, LEVD). Esta diligencia de investigación es llevada a cabo por las fuerzas y cuerpos de seguridad del Estado, y consiste en averiguar la existencia e intensidad de la situación de riesgo para la víctima a través de la toma de declaración a la misma, a su entorno y de la recopilación de informes a los servicios sociales, sanitarios y administrativos que corresponda. Para un examen en profundidad de este modelo véase el Protocolo médico-forense de valoración urgente del riesgo de violencia de género, disponible en: https://bit.ly/3bzUKhW, así como las reflexiones al respecto realizadas por Sánchez López (2019).

49 También se refiere a la irrelevancia del consentimiento en el Protocolo de Palermo Serughetti (2018: 93) cuando relata que las dos posiciones enfrentadas en la negociación previa a su adopción —abolicionista y regulacionista- pudieron considerarse vencedoras porque en el texto del Protocolo «la única referencia a la prostitución está contenida en la fórmula "explotación de la prostitución ajena", mientras que la definición de trata especifica que "el consentimiento de la víctima de la trata de personas a la explotación" debe considerarse "irrelevante" si se utiliza cualquier forma de coacción contra ella (o él)». 
En la Convención de $1949^{50}$, evocada también en la sentencia, el consentimiento es irrelevante porque no se entiende concurrente nunca en los casos de prostitución. Es decir, la irrelevancia del consentimiento no significa lo mismo según uno y otro parámetro, que son indistintamente utilizados por el Tribunal sin tener en cuenta la ratio que se encontraba detrás de la aprobación de cada uno de estos instrumentos.

A mi juicio, el problema es quizá más simple. Y es que la sentencia ni siquiera atiende a la cuestión del consentimiento de forma consciente ${ }^{51}$, anulando la relevancia de la cuestión al apreciar la existencia indiciaria de fuerza o coacción sobre la víctima cuando, como afirma Serughetti (2018: 83), "la dicotomía fuerza versus consentimiento es tan esencial para las posiciones que representan toda la prostitución como violencia, como para las que distinguen entre prácticas de trabajo sexual voluntarias e involuntarias, es decir, entre agentes sexuales y víctimas sexuales» ${ }^{52}$. Por tanto, fuerza y consentimiento son dos elementos indisociables en cualquier reflexión sobre si se dan o no las situaciones prohibidas por el art. $4 \mathrm{CEDH}$.

De todos modos, en el asunto $S$. $M$., no es posible saber si la coacción o la fuerza que estima concurrente la sentencia fue suficiente o no para anular la capacidad de consentimiento de la víctima porque el Tribunal no entra al fondo de esta cuestión. Tampoco sabemos si el TEDH asume que este tipo de fuerza (que solo ha de aparecer como indicio de prueba, para forzar la activación de las obligaciones positivas del Estado en relación con la investigación) es la que ejercen habitualmente los proxenetas y, por tanto, va indisolublemente unida al beneficio obtenido por la explotación ajena. La indefinición es tan grande que plantea más dudas que certezas y viene a

50 Convenio para la Represión de la Trata de Personas y de la Explotación de la Prostitución Ajena, firmado en Lake Success, Nueva York, el 21 de marzo de 1950, conocido como Convenio de 1949, al ser adoptado por la Asamblea General en su resolución 317 (IV), de 2 de diciembre de 1949.

$51 \mathrm{Y}$ esto es problemático. No puede negarse que la cuestión del consentimiento es la clave del debate entre abolicionismo y regulacionismo de la prostitución si identificamos en torno a estos dos términos las distintas corrientes que reflexionan y se pronuncian sobre esta cuestión. Seruguetti (2018: 82), con un planteamiento interesante, se refiere al feminismo que sostiene la imposibilidad de consentimiento en la prostitución como «dominance feminism» (abolicionismo), y al que asume la posibilidad de consentir en prestar servicios sexuales a cambio de dinero «choicen feminism» (regulacionismo).

52 Esta autora considera que, en particular para el «choice feminism», el consentimiento es el factor que distingue el trabajo sexual de la trata, la explotación sexual y la violencia sexual y de género (Serughetti, 2018: 83). 
abonar la indiferenciación entre prostitución y trata, que en nada ayuda a la superación de uno y otro problema.

Quizá el TEDH no está llamado a resolver esta diatriba, inicialmente ética y política ${ }^{53}$, pero con una clarísima proyección jurídica sucesiva, ante la ausencia de consensos internacionales, que se evidencia también en el seno del propio movimiento feminista ${ }^{54} . Y$ bien sabemos que el TEDH no suele resolver problemas de calado ético o moral en los que no existe un cierto consenso internacional que le permita apelar a la existencia de un mínimo ius cogens. Posiblemente la conclusión que cabe alcanzar sea la que defiende Pamela Haag (1999) cuando sostiene que el concepto abstracto de consentimiento solo se hace inteligible en un contexto situado específico. Y lo curioso es que esto es lo que suele hacer el TEDH: resolver los asuntos que se le plantean en el marco exclusivo del contexto situado específico que presentan. Sin embargo, en este caso, queriendo formular el juicio en estos términos, se abren una serie de problemas teóricos que, sin duda, el Tribunal estará llamado a enfrentar de nuevo en el futuro.

Por tanto, siendo sumamente positivos el esfuerzo del TEDH y su aproximación metodológica a los problemas abordados, las dos sentencias nos muestran cómo la traslación de cánones de enjuiciamiento desarrollados para otros fenómenos pueden ser insuficientes a la hora de valorar situaciones de violencia de género que tienen una base discriminatoria estructural muy clara. Consentimiento y riesgo son dos conceptos complejos que nos muestran los límites de la aproximación del TEDH. Dos conceptos en los que es preciso seguir trabajando desde la teoría feminista del derecho.

\section{Bibliografía}

Alcoceba Gallego, A. (2013). La violencia contra la mujer en el seno del Consejo de Europa. La sentencia del TEDH en el caso Opuz c. Turquía. En F. Mariño

53 Para calibrar la dificultad de la cuestión puede evocarse que algunos autores hablan de las «consent wars» en el momento de la negociación del Protocolo de Palermo. A ello se refiere Serughetti (2018: 92).

54 Sin ir más lejos, en el contexto español podemos encontrar interesantísimos trabajos teóricos tanto en defensa de la posición abolicionista, que niega la concurrencia del consentimiento libre en los supuestos de prostitución (De Miguel, 2016; Cobo Bedia, 2012), como en defensa de la posición regulacionista, que asume que en determinadas circunstancias la prostitución puede ser una prestación de servicios parangonable a cualquier otra prestación laboral (Boza, 2018; Carmona Salgado, 2015). 
(dir.) y A. Alcoceba Gallego y F. Quispe Remón (coords.). Feminicidio: el fin de la impunidad (pp. 177-190). Valencia: Tirant lo Blanch.

Boza Moreno, E. (2018). La prostitución como trabajo. Valencia: Tirant lo Blanch.

Cardoso Onofre de Alencar, E. (2019). Violencia por razón de género en la pareja y estereotipos en el sistema de justicia: lecciones del Comité de la CEDAW. FEMERIS: Revista Multidisciplinar de Estudios de Género, 4 (3), 29-52. Disponible en: https://doi.org/10.20318/femeris.2019.4927.

Carmona Cuenca, E. (2013). Mujeres prostituidas y mujeres víctimas de la trata: la incorporación de la perspectiva de género a la jurisprudencia del Tribunal Europeo de Derecho Humanos. En D. Giménez Gluck et al. (coord.). La discriminación múltiple en los ordenamientos jurídicos español y europeo (pp. 223-244). Valencia: Tirant lo Blanch.

- (2015). La igualdad de género en el Tribunal Europeo de Derechos Humanos: un reconocimiento tardío en relación con el Tribunal de Justicia de la Unión Europea. Revista Española de Derecho Constitucional, 104, 297-328. Disponible en: https://doi.org/10.18042/cepc/redc.104.10.

- (ed.) (2015). La perspectiva de género en los sistemas europeo e interamericano de derechos humanos. Madrid: Centro de Estudios Políticos y Constitucionales.

- (2018). Los principales hitos jurisprudenciales del Tribunal Europeo de Derechos Humanos en materia de igualdad de género. Teoría y Realidad Constitucional, 42, 311-334. Disponible en: https://doi.org/10.5944/trc.42.2018.23635.

Carmona Salgado, C. (2015). Trata de seres humanos para su explotación sexual. Argumentos a favor de una regulación española que normalice el ejercicio por adultos de la prostitución voluntaria. La Ley Penal: Revista de Derecho Penal, Procesal y Penitenciario, 113, 3.

Castro Sánchez, C. (2005). Nuevas formas de esclavitud: mujeres inmigrantes y trabajo doméstico. Comentario de la Sentencia del TEDH, Siliadin c. Francia, de 26 de julio de 2005. Revista General de Derecho Europeo, 8.

Cobo Bedia, R. (2012). Informe proyecto investigación: Consentimiento y coacción. Prostitución y politicas públicas 2010-2012. Madrid: Instituto de la Mujer y para la Igualdad de Oportunidades. Disponible en: https://bit.ly/3byreZX.

Copelon, R. (1994). Recognizing the egregious in the everyday: Domestic violence as torture. Columbia Human Rights Law Review, 25, 291-367. Disponible en: https://bit.ly/3CNJydC.

De Miguel Álvarez, A. (2016). Neoliberalismo sexual: el mito de la libre elección. Madrid: Cátedra.

Enrich i Mas, M. (2018). Discriminación y violencia de género: jurisprudencia del Tribunal Europeo de Derechos Humanos. En C. Morte (coord.). Human rights in a global world: essays in honour of judge Luis López Guerra (pp. 143-166). Oisterwijk: Wolf Legal Publishers.

Haag, P. (1999). Consent: Sexual Rights and the Transformation of American Liberalism. Ithaca, Nueva York: Cornell University Press. Disponible en: https://doi. org/10.7591/9781501725401. 
López-Jacoiste Díaz, E. (2009). Violencia doméstica y malos tratos en el Tribunal Europeo de Derechos Humanos. Anuario de Derecho Internacional, 25, 383-412. Medina, G. (2014). La violencia contra las mujeres en la jurisprudencia del Tribunal Europeo de Derechos Humanos. Actualidad Jurídica Iberoamericana, 1, 43-52.

Mowbray, A. R. (2004). The development of positive obligations under the European Convention on Human Rights by the European Court of Human Rights. Oxford: Portland Hart Publishing.

Plouffe-Malette, K. (2020). Quinze ans de jurisprudence de la Cour européenne des droits de l'homme sur la traite des êtres humains: de l'affaire Siliadin c. France à l'arrêt de Grande Chambre S. M. c. Croatie. Revue Québécoise de Droit International, 14. Disponible en: https://doi.org/10.7202/1078547ar.

Queralt Jiménez, A. (2012). La violencia de género como discriminación de las mujeres por razón de sexo en la jurisprudencia del Tribunal de Estrasburgo: un camino recién iniciado. En J. Saura (dir.). Reconocimiento y protección de derechos emergentes en el sistema europeo de derechos humanos (pp. 251-296). Madrid: Dykinson.

Russo, N. F. y Pirlott, A. (2006). Gender-based violence: Concepts, methods, and findings. En F. L. Denmark, H. H. Krauss, E. Halpern y J. A. Sechzer (eds.). Violence and exploitation against women and girls (pp. 178-205). New Jersey: Blackwell Publishing.

Sánchez López, B. (2019). La diligencia policial de valoración del riesgo de violencia de género en el sistema Viogén. Foro: Revista de Ciencias Jurídicas y Sociales, 22 (1), 119-130. Disponible en https://doi.org/10.5209/foro.66637.

Sánchez Perea, P. (2019). Sobre la libertad de ejercicio en la prostitución: tres argumentos y una estrategia abolicionista a debate. Encrucijadas. Revista Crítica de Ciencias Sociales, 17. Disponible en: https://bit.ly/2ZQlzLS.

Serra Cristóbal, R. (2015). Una llamada de atención sobre un mercado de víctimas invisibles: caso Rantsev contra Chipre y Rusia (Tribunal Europeo de Derechos Humanos). En M. Revenga Sánchez y C. García Pascual (coords.). Decisiones básicas en materia de violaciones de derechos humanos (pp. 279-308). Madrid: Agencia Estatal Boletín Oficial del Estado; Centro de Estudios Políticos y Constitucionales.

Serughetti, G. (2018). Rethinking force and consent, victimisation and agency: A feminist approach to prostitution policy. Femeris: Revista Multidisciplinar de Estudios de Género, 3 (2), 79-107. Disponible en: https://doi.org/10.20318/ femeris.2018.4321.

Stoyanova, V. (2016). L. E. v. Greece: Human Trafficking and the Scope of States' Positive Obligations under the ECHR. European Human Rights Law Review, 3 , 190- 230. Disponible en: https://bit.ly/3q2q6Gj.

Stoyanova, V. (2017). Human Trafficking and Slavery Reconsidered. Conceptual Limits and States' Positive Obligations. European Law (Front Matter). En Human Trafficking and Slavery Reconsidered. Cambridge, U. K.: Cambridge University Press. Disponible en: https://bit.ly/3nRCAxK. 
Sudre, F. (1995). Les obligations positives dans la jurisprudence européenne des droits de l'homme. Revue Trimestrielle des Droits de L'homme, 363-384.

Trujillo del Arco, A. (2020). El asunto S. M. c. Croacia: del nuevo abolicionismo de la prostitución en el CEDH y del desastre interpretativo del TEDH. Revista General de Derecho Europeo, 51.

Wertheimer, A. (2003). Consent to sexual relations. Cambridge, U. K.: Cambridge UniversityPress. Disponible en: https://doi.org/10.1017/CBO9780511610011. 